\title{
LAND COVER CHANGE ANALYSIS IN MEXICO USING 30M LANDSAT AND 250M MODIS DATA
}

\author{
R. R. Colditz ${ }^{\text {a, } * \text { R. M. Llamas }}{ }^{\text {a }}$, R. A. Ressl ${ }^{\text {a }}$ \\ ${ }^{a}$ National Commission for the Knowledge and Use of Biodiversity (CONABIO), Av. Liga Periférico-Insurgentes Sur 4903, Parques \\ del Pedregal, Tlalpan, CP 14010, Mexico City, DF, Mexico - (rene.colditz, ricardo.llamas, rainer.ressl)@conabio.gob.mx
}

$3^{\text {th }}$ International Symposium on Remote Sensing of Environment (ISRSE)

KEY WORDS: Land cover time series, Change detection, Spatial-temporal analysis, MODIS, Mexico

\begin{abstract}
:
Change detection is one of the most important and widely requested applications of terrestrial remote sensing. Despite a wealth of techniques and successful studies, there is still a need for research in remote sensing science. This paper addresses two important issues: the temporal and spatial scales of change maps. Temporal scales relate to the time interval between observations for successful change detection. We compare annual change detection maps accumulated over five years against direct change detection over that period. Spatial scales relate to the spatial resolution of remote sensing products. We compare fractions from $30 \mathrm{~m}$ Landsat change maps to $250 \mathrm{~m}$ grid cells that match MODIS change products. Results suggest that change detection at annual scales better detect abrupt changes, in particular those that do not persist over a longer period. The analysis across spatial scales strongly recommends the use of an appropriate analysis technique, such as change fractions from fine spatial resolution data for comparison with coarse spatial resolution maps. Plotting those results in bi-dimensional error space and analyzing various criteria, the "lowest cost", according to a user defined (here hyperbolic) cost function, was found most useful. In general, we found a poor match between Landsat and MODIS-based change maps which, besides obvious differences in the capabilities to detect change, is likely related to change detection errors in both data sets.
\end{abstract}

\section{INTRODUCTION}

Change detection of land cover and land use is one of the foremost applications of remote sensing data. Even though well studied over the past five decades, there is still on-going research in many fields such as method development (see summaries in $\mathrm{Lu}$ et al. (2004) and Coppin et al (2004)), combining spatial scales and multiple data sets (Colditz et al. 2012a), application-specific developments, e.g. for urban planning (Tapiador and Casanova 2003), or robust regional to continental change detection with automated methods (Pouliot et al. 2014). For successful change studies one needs to consider several factors, such as available resources, image availability, accessibility to ground observations and ancillary data, availability and experience with change detection algorithms, area of expertise, intended use of the product, etc. (Kennedy et al. 2009).

This study addresses two important issues: temporal and spatial scales of change detection. The temporal scale of change is important and one should select the appropriate data sets carefully. For instance, abrupt change may only persist for a short period of time while subtle change processes may not be detectable at short temporal intervals. For temporal scales, the study analyzes annual change products over five years which were accumulated and compared to direct change detection between the initial and final year. Differences in spatial scales are studied using data of different spatial resolution; in this study comparing change maps obtained from $30 \mathrm{~m}$ Landsat data to $250 \mathrm{~m}$ MODIS products. Landsat change maps were generated for minimum mapping units (MMUs) of 1ha, 5ha, and 10ha. For adequate map comparison across spatial resolutions an algorithm calculated the fraction of change from fine spatial resolution data for each coarse cell, and several criteria for defining the appropriate change fraction were tested.

\section{DATA AND STUDY AREA}

The Canada Centre for Remote Sensing (CCRS) of Natural Resources Canada (NRCan) processed MODIS calibrated radiances for the entire North American continent and provided monthly image composites to an international research network. Specifically, the following processing steps were carried out: projection to Lambert Azimuthal Equal Area (LAEA), downscaling to obtain images of $250 \mathrm{~m}$ spatial resolution for all 7 reflective bands, and compositing to monthly data (for overview see Latifovic et al. 2012). In this study we employed monthly composites of MODIS data from 2005 to 2010.

Table 1 lists all Landsat images of path 046 - row 020 that were analyzed in this study. All corresponding Landsat 7ETM+ images were composited to reduce data gaps in the primary image by filling with valid pixels from a secondary image. In 2008, no cloud-free data were available for the period March to May. Therefore a set, marked as $2008 \mathrm{~A}$, was used for change detection with the composite of 2007 and 2008B with data from 2009; all other composites were employed for both pairs. All images were preprocessed using LEDAPS (Masek et al. 2006) for obtaining surface reflectance and FMASK (Zhu et al. 2012) for detecting, clouds, shadow and invalid data due to the failure of the scan-line corrector since May 2003.

* Corresponding author 


\begin{tabular}{|c|c|c|c|}
\hline Year & Sensor & Primary & Secondary \\
\hline 2005 & L7 ETM ${ }^{+}$ & April $10^{\text {th }}$ & April $26^{\text {th }}$ \\
\hline 2006 & L7 $\mathrm{ETM}^{+}$ & April $29^{\text {th }}$ & April $13^{\text {th }}$ \\
\hline 2007 & L7 ETM ${ }^{+}$ & March $15^{\text {th }}$ & April $16^{\text {th }}$ \\
\hline 2008A & L7 ETM ${ }^{+}$ & January $29^{\text {th }}$ & January $13^{\text {th }}$ \\
\hline 2008B & L7 ETM ${ }^{+}$ & August $24^{\text {th }}$ & November $28^{\text {th }}$ \\
\hline 2009 & L7 ETM ${ }^{+}$ & April $5^{\text {th }}$ & May $7^{\text {th }}$ \\
\hline 2010 & L5 TM & January $26^{\text {th }}$ & NA \\
\hline
\end{tabular}

Table 1. Sensor and dates of Landsat images per year.

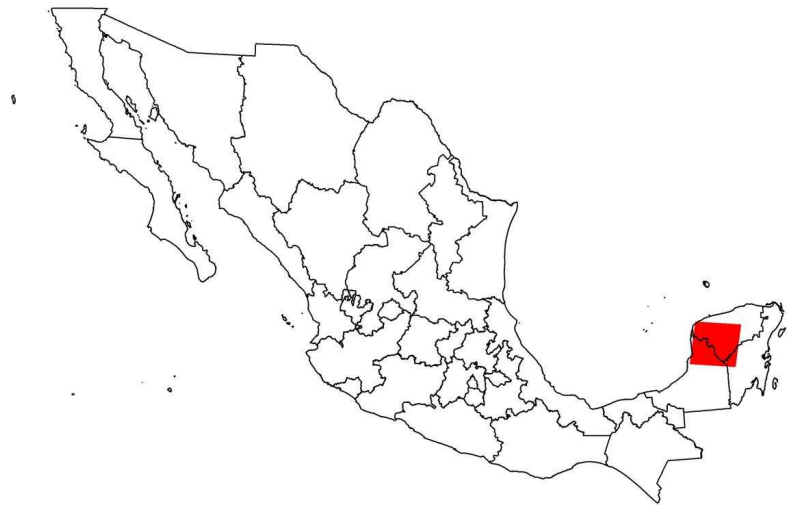

Figure 1. Study areas: the national terrestrial territory of Mexico with its states and location of Landsat path-row 046-020 on the Yucatan peninsula, marked in red.

In a first test, the national terrestrial territory of Mexico (1.972 Mio $\mathrm{km}^{2}$ ) will be analyzed using MODIS data. Next, the area of path-row 046-020 will be studied in detail (Figure 1) using Landsat and MODIS-based change detection products. This region, located in the north-western portion of the Yucatan peninsula and south of the city of Merida, depicts a transition from deciduous to evergreen broadleaf tropical forests towards the East. Slash-and-burn agriculture, such as frequently applied to Milpas, is characteristic to fertilize poor karstic soils for a short period of 3-5 years, planting maize, squash, and beans.

\section{METHODS}

\subsection{Change detection}

3.1.1 MODIS data: A base-line land cover classification with 19 classes for North America (15 for Mexico) using a standardized, LCCS-compatible legend was generated for the year 2005 (Latifovic et al. 2012). For Mexico, supervised decision tree (C5.0, Quinlan 1993) ensemble classifiers were trained with a 121,000 sample points from field-based analysis and on-screen digitalization (Colditz et al, 2012b). A first version of this map was recently improved in selected areas mainly for classes "urban and built-up" and "water" (Colditz et al. 2014a).

An algorithm was developed to obtain potential areas of land cover change using normalized bi-annual difference images for all month and bands as well as additional data such as the NDVI and texture filters for improved edge detection. An algorithm was trained with Landsat images for a large area in northern Mexico for the period 2005 to 2010. Optimization resulted in the following thresholds: 1 and 99 percentile of each difference image and a frequency of $25 \%$ from all features (Colditz et al. 2014b).
Next, a map updating strategy was used to assign new land cover classes to pixels flagged as potential change (Colditz et al. 2014a). Therefore there are two change products: (1) potential change by biannual differences and (2) actual change for areas with a change in the class label. In this study we employ maps without minimum mapping unit, thus the smallest change object is $6.25 \mathrm{ha}$, the area of a $250 \mathrm{~m}$ MODIS pixels.

3.1.2 Landsat data: Change from Landsat images was detected by visual interpretation using two analysts: one detected changes between 2005 and 2010 directly, the other consecutive annual changes between all years. The analysts digitized polygons at high spatial detail and also identified areas which they could not map, either due to clouds or too large data gaps between scan lines. To ensure consistency, a third analyst verified and, if necessary, revised polygons. For standardized products, MMUs of 1ha, 5ha, and 10ha were applied.

\subsection{Change analysis}

From each sensor two data change sets were generated: (1) direct land cover change between 2005 and 2010 without analyzing the years in between and (2) annual consecutive land cover change between 2005 and 2010 (2005-2006, 2006-2007, 2007-2008, 2008-2009, and 2009-2010). The latter was aggregated to accumulated annual change between 2005 and 2010 and compared to direct land cover change for the same period. For MODIS there are potential change maps, for Landsat change products were obtained at $1 \mathrm{ha}$, 5ha, and $10 \mathrm{ha}$ between 2005 and 2010.

3.2.1 Change area and polygons: The area of each change map, effectively the number of pixels detected as change, is calculated and expressed in area as square kilometre and percent. In addition, the number of patches of change, i.e. a pixel or group of connected pixels surrounded by pixels of no change, was calculated using the eight-neighbour rule and reported as simple count and number of patches per square kilometre. The relative numbers are useful to compare change results across different temporal and spatial scales.

3.2.2 Change comparison at the same resolution: A simple matrix (Figure 2) was used to compare two maps of no change (0) and change (1) of the same resolution of which the common change area $\left(\mathrm{N}_{11}\right)$ was analyzed. Specifically the error (E), expressed in percent, of change in map $\mathrm{A}$ against $\mathrm{B}$ and vice versa was calculated following equations (1) and (2).

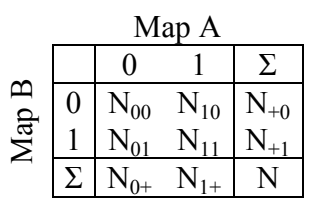

Figure 2: Matrix of correspondence between change (1) in map $\mathrm{A}$ and $\mathrm{B}$.

$$
\begin{aligned}
& E_{A}=1-\frac{N_{11}}{N_{1+}} \\
& E_{B}=1-\frac{N_{11}}{N_{+1}}
\end{aligned}
$$




\begin{tabular}{|c|c|c|c|c|c|c|c|c|}
\hline & \multicolumn{4}{|c|}{ Potential change } & \multicolumn{4}{|c|}{ Actual change } \\
\hline & $\mathrm{km}^{2}$ & Area $\%$ & Patches & Patches $/ \mathrm{km}^{2}$ & $\mathrm{~km}^{2}$ & Area \% & Patches & Patches $/ \mathrm{km}^{2}$ \\
\hline $2005-2006$ & 6187.94 & 0.3156 & 7647 & 0.0039 & 1500.31 & 0.0765 & 4519 & 0.0023 \\
\hline $2006-2007$ & 5621.94 & 0.2867 & 8094 & 0.0041 & 1643.06 & 0.0838 & 5542 & 0.0028 \\
\hline $2007-2008$ & 5103.06 & 0.2602 & 7433 & 0.0038 & 1571.31 & 0.0801 & 5034 & 0.0026 \\
\hline $2008-2009$ & 6265.50 & 0.3195 & 8268 & 0.0042 & 2196.25 & 0.1120 & 6228 & 0.0032 \\
\hline $2009-2010$ & 6535.25 & 0.3333 & 8300 & 0.0042 & 1996.25 & 0.1018 & 5866 & 0.0030 \\
\hline $\begin{array}{l}2005-2010 \\
\text { accumulative }\end{array}$ & 16861.56 & 0.8598 & 22237 & 0.0113 & 6572.88 & 0.3352 & 14166 & 0.0072 \\
\hline $\begin{array}{l}2005 \text { - } 2010 \\
\text { direct }\end{array}$ & 7023.31 & 0.3582 & 12258 & 0.0063 & 3304.94 & 0.1685 & 9206 & 0.0047 \\
\hline
\end{tabular}

Table 2. Area and patches for potential and actual change of MODIS data at the national scale.

3.2.3 Change comparison at different resolutions: Analyzing change of maps with different spatial resolution is more complicated. We employed an algorithm which calculates the area proportions (or fractions) of change from a fine spatial resolution map in a coarse spatial resolution grid (Colditz et al. 2012a). Next, we calculate the matrix of Figure 2 and errors of equations (1) and (2) for all potential fractions $(0 \%$ to $100 \%$ at $1 \%$ intervals) and present this result in bi-dimensional space $\left(E_{A}, E_{B}\right)$. There are several ways to determine the best change fraction, e.g. the $50 \%$ fraction, i.e. at least $50 \%$ of the coarse cell were mapped as change in the fine spatial resolution pixel, the fraction at which $\mathrm{E}_{\mathrm{A}}$ and $\mathrm{E}_{\mathrm{B}}$ are equal (if they intersect), or the lowest cost using a cost function such as the hyperbolic in equation 3. In addition, the Pareto boundary for the lowest achievable error bound (Boschetti et al. 2004) was calculated for each fine spatial resolution set.

$$
\operatorname{Cost}(x)=1-\left[\left(1-E_{A}\right) \cdot\left(1-E_{B}\right)\right]
$$

\section{RESULTS AND ANALYSIS}

\subsection{MODIS based change at the national scale}

The MODIS-based change detection was developed for the national area of Mexico and therefore shall be analyzed first for this extent. Table 2 shows the area in square kilometres and percent and patches as absolute number and per square kilometre. The area of potential change is, on average, three times larger than actual change of class labels. Even though there are more patches of potential change than actual change, the average ratio of 1.46 is lower than for area.

Notable is also the sum of annual changes between 2005 and 2010 , which is much larger than the accumulated change area, e.g. $29,713 \mathrm{~km}^{2}$ compared to $16,861 \mathrm{~km}^{2}$ for potential change. This indicates that a significant area was mapped several times as change. Figure $3 \mathrm{~A}$ shows the percent of area that was detected one to five times as change in annual change maps. For potential change, $42 \%$ of the area was at least twice detected as change and $3.3 \%$ of the change pixels were detected in all biannual change maps. It is clear that actual change was less likely detected several times and this number could be further reduced be applying rules of change persistency similar to Pouliot et al. (2009).

The third notable result is that direct change between 2005 and 2010 is clearly lower than accumulative annual change. In fact, many potential annual changes are only slightly smaller than 2005-2010 direct change. For actual change the difference is higher but direct change is still only half of the area of accumulative annual change. This indicates that longer time spans between dates may not detect several changes that occur at shorter intervals.

The change maps between 2005 and 2010 obtained by direct comparison and accumulative annual changes were compared and summarized in a matrix similar to Figure 2. Table 3 shows the respective errors for accumulative and direct change. It is clear that the error is higher for accumulative change as a 2.5 times larger area was detected, thus at best the error cannot be lower than $60 \%$. Still, only half of the that area $(21.9 \%$ of accumulative change) was also found with direct change. Errors for direct change are lower but still approximately half of the total change area. This indicates that both maps are clearly different and mark changes at distinct temporal scales.

\subsection{MODIS-based change for Yucatan}

Table 4 reports change areas and patches from MODIS for the study site on the Yucatan peninsula. The total area (column Yucatan) corresponds to the valid area of Landsat data $(>50 \%$ of valid area proportion) and relative numbers such as area in percent and patches by area are relative to this number.
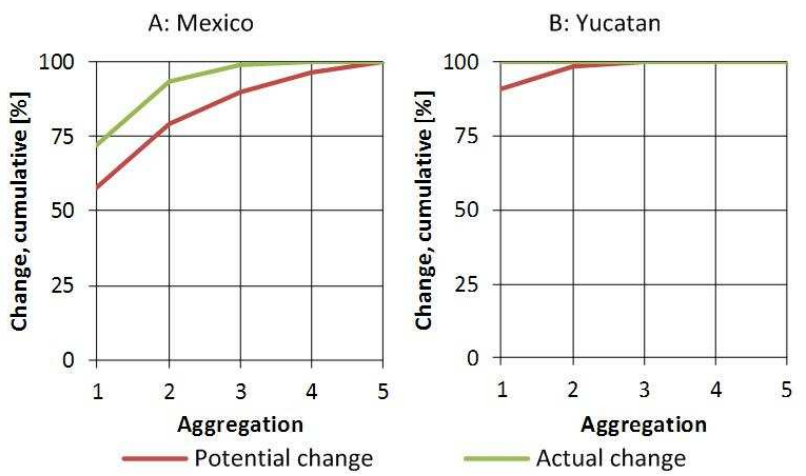

Figure 3. Proportion of change pixels detected one to five times in bi-annual change maps for Mexico (A) and Yucatan (B).

\begin{tabular}{lcclcc}
\hline Error & \multicolumn{2}{c}{ Mexico } & & \multicolumn{2}{c}{ Yucatan } \\
\cline { 2 - 3 } \cline { 5 - 6 } & Potential & Actual & & Potential & Actual \\
\hline Accumulative & 78.15 & 77.88 & & 65.07 & 44.69 \\
Direct & 47.53 & 56.01 & & 63.67 & 65.98 \\
\hline
\end{tabular}

Table 3. Error between direct change and accumulative annual change maps between 2005 and 2010 for Mexico and Yucatan. 


\begin{tabular}{|c|c|c|c|c|c|c|c|c|c|}
\hline \multirow[t]{2}{*}{ Change } & \multirow{2}{*}{$\frac{\text { Yucatan }}{\mathrm{km}^{2}}$} & \multicolumn{4}{|c|}{ Potential change } & \multicolumn{4}{|c|}{ Actual change } \\
\hline & & $\mathrm{km}^{2}$ & Area $\%$ & Patches & Patches $/ \mathrm{km}^{2}$ & $\mathrm{~km}^{2}$ & Area \% & Patches & Patches $/ \mathrm{km}^{2}$ \\
\hline $2005-2006$ & 14364 & 1.44 & 0.0100 & 48 & 0.0033 & 0.94 & 0.0065 & 25 & 0.0017 \\
\hline $2006-2007$ & 13807 & 10.75 & 0.0779 & 72 & 0.0052 & 7.06 & 0.0511 & 47 & 0.0034 \\
\hline $2007-2008$ & 27250 & 6.50 & 0.0239 & 65 & 0.0024 & 2.13 & 0.0078 & 32 & 0.0012 \\
\hline $2008-2009$ & 26697 & 32.69 & 0.1224 & 363 & 0.0136 & 9.19 & 0.0344 & 100 & 0.0037 \\
\hline $2009-2010$ & 32515 & 6.13 & 0.0188 & 65 & 0.0020 & 3.06 & 0.0094 & 40 & 0.0012 \\
\hline $\begin{array}{l}2005-2010 \\
\text { accumulative }\end{array}$ & 33712 & 52.06 & 0.1544 & 255 & 0.0076 & 22.38 & 0.0664 & 106 & 0.0031 \\
\hline $\begin{array}{l}2005-2010 \\
\text { direct }\end{array}$ & 32466 & 45.69 & 0.1407 & 182 & 0.0056 & 33.25 & 0.1024 & 119 & 0.0037 \\
\hline
\end{tabular}

Table 4. Area and patches for potential and actual change of MODIS data for Yucatan.

\begin{tabular}{|c|c|c|c|c|c|c|c|c|c|c|c|c|c|}
\hline \multirow[t]{2}{*}{ Change } & \multirow{2}{*}{$\frac{\text { Yucatan }}{\mathrm{km}^{2}}$} & \multicolumn{4}{|c|}{1 ha } & \multicolumn{4}{|c|}{5 ha } & \multicolumn{4}{|c|}{ 10ha } \\
\hline & & $\mathrm{km}^{2}$ & $\begin{array}{c}\text { Area } \\
\%\end{array}$ & Patches & $\begin{array}{c}\text { Patches } \\
/ \mathrm{km}^{2}\end{array}$ & $\mathrm{~km}^{2}$ & $\begin{array}{c}\text { Area } \\
\%\end{array}$ & Patches & $\begin{array}{l}\text { Patches } \\
/ \mathrm{km}^{2}\end{array}$ & $\mathrm{~km}^{2}$ & $\begin{array}{c}\text { Area } \\
\%\end{array}$ & Patches & $\begin{array}{l}\text { Patches } \\
/ \mathrm{km}^{2}\end{array}$ \\
\hline $2005-2006$ & 13845 & 32.48 & 0.23 & 667 & 0.0482 & 21.73 & 0.15 & 182 & 0.0131 & 17.08 & 0.12 & 106 & 0.0077 \\
\hline $2006-2007$ & 13300 & 26.93 & 0.20 & 446 & 0.0335 & 21.58 & 0.16 & 170 & 0.0128 & 17.34 & 0.13 & 98 & 0.0074 \\
\hline $2007-2008$ & 26418 & 26.01 & 0.09 & 415 & 0.0157 & 21.19 & 0.08 & 201 & 0.0076 & 16.46 & 0.06 & 118 & 0.0045 \\
\hline $2008-2009$ & 25782 & 26.21 & 0.10 & 675 & 0.0262 & 17.53 & 0.06 & 201 & 0.0078 & 11.43 & 0.04 & 84 & 0.0033 \\
\hline $2009-2010$ & 32056 & 15.39 & 0.04 & 316 & 0.0099 & 10.80 & 0.03 & 91 & 0.0028 & 7.16 & 0.02 & 35 & 0.0011 \\
\hline $\begin{array}{l}2005-2010 \\
\text { accumulative }\end{array}$ & 33337 & 123.98 & 0.37 & 2264 & 0.0679 & 90.45 & 0.27 & 760 & 0.0228 & 67.52 & 0.20 & 404 & 0.0121 \\
\hline $\begin{array}{l}2005-2010 \\
\text { direct }\end{array}$ & 31843 & 505.91 & 1.58 & 7709 & 0.2421 & 393.05 & 1.23 & 2889 & 0.0907 & 285.51 & 0.89 & 1150 & 0.0361 \\
\hline
\end{tabular}

Table 5. Area and patches for changes of Landsat with 1ha, 5ha and 10ha minimum mapping unit for Yucatan.

In comparison to area percentages at the national scale, MODIS detected clearly less changes in the Yucatan site. However, the number of patches per area did not reduce notably, which indicates that the area of change patches is much smaller in Yucatan than at the national scale.

The percentage of annual changes detected several times is lower. In fact, Figure 3B depicts only some notable double and almost no triple detection for potential changes while all actual changes occurred only once.

The correspondence between direct and accumulative change maps between 2005 and 2010 in Table 3 show an reversal in the magnitude of errors with a the higher area of accumulative versus direct change for the potential change maps and vice versa for actual change. Overall, however, the errors are still quite high at the local level for Yucatan.

\subsection{Landsat-based change}

Annual Landsat-based change areas for the Yucatan site (Table 5) depict area proportions similar to the national scale of MODIS but clearly higher than those of the local level. An average decrease of $25 \%$ in change area is indicated between 1 and 5ha MMU and 45\% between 1 and 10ha. Across all minimum mapping units, however, there is the four times higher area for direct changes between 2005 and 2010 as compared to accumulative annual changes for the same period, a contradictory result on comparison to the findings obtained from MODIS.

The numbers of patches reduce, on average, by $65 \%$ between 1 and 5 ha and $82 \%$ between 1 and 10 ha. This marked decrease indicates a high number of small polygons. In comparison to MODIS at the national scale the number of change patches per square kilometre is approximately a magnitude higher for 1 ha, roughly the same for 5 ha which is similar to the 6.25 ha area of a $250 \mathrm{~m}$ MODIS pixel, and a magnitude lower for $10 \mathrm{ha}$. This indicates the importance of spatial resolution for detecting change.

The comparison of Landsat change maps of accumulative annual changes and direct changes between 2005 and 2010 (Table 6) shows the expected pattern: a high error for direct changes due to the much larger area detected as changes. The numbers vary only slightly among minimum mapping units. There was no noteworthy multiple detection of Landsat pixels in annual change maps.

\subsection{Comparison of Landsat and MODIS-based change}

Comparison between 30m Landsat and 250m MODIS products requires a technique which relates the fine spatial resolution data to coarse spatial resolution cells. In this study we calculate the fraction of change from Landsat products with different MMUs for each $250 \mathrm{~m}$ cell and compare this result to potential change from MODIS.

\begin{tabular}{lccc}
\hline Error & 1ha & 5ha & 10ha \\
\hline Accumulative & 43.97 & 41.90 & 40.88 \\
Direct & 86.86 & 87.25 & 86.68 \\
\hline
\end{tabular}

Table 6. Error between direct change and accumulative annual change maps between 2005 and 2010 for 1ha, 5ha and 10ha minimum mapping units. 


\section{A: Pareto boundaries}

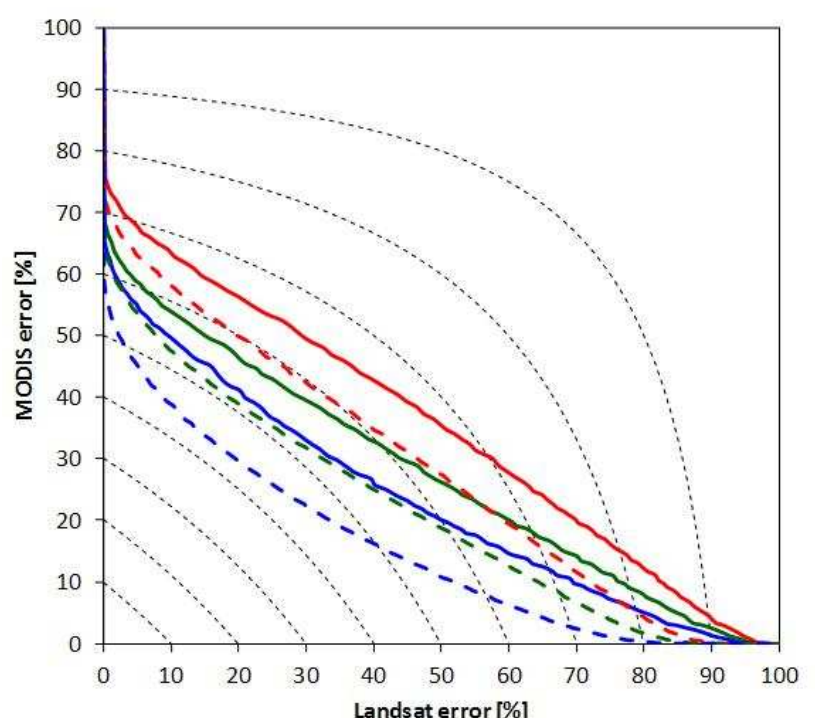

\section{B: MODIS-Landsat comparison}

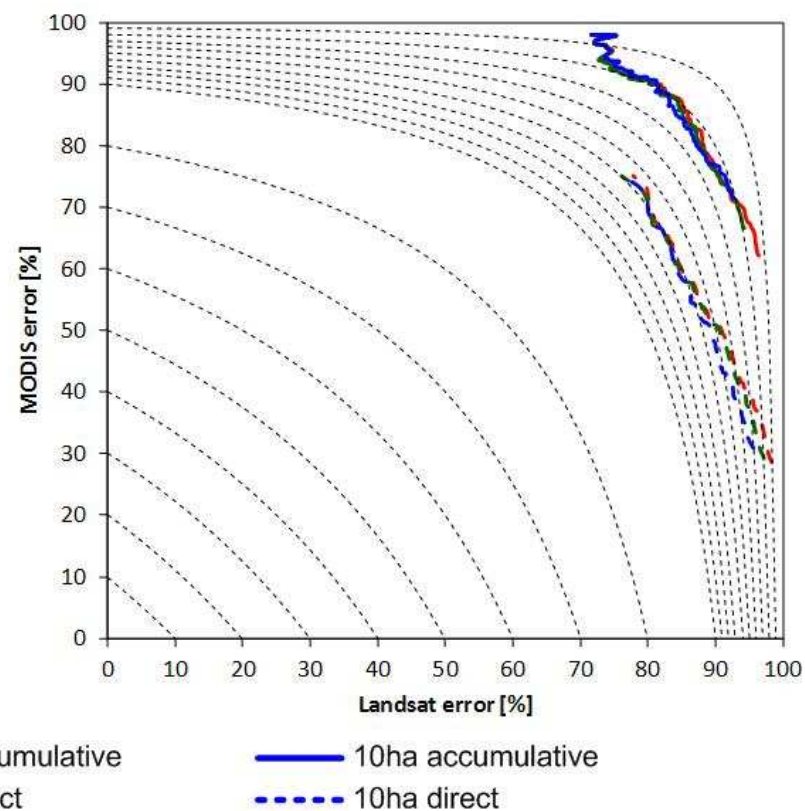

Figure 4. MODIS-Landsat error plots for Pareto boundaries (A) as best achievable result and Landsat-MODIS data comparison (B) using direct and aggregated annual change between 2005 and 2010 from MODIS potential changes and Landsat change with 1ha, 5ha and 10ha MMU.

There are multiple criteria to define the most appropriate fraction and corresponding errors which we will explore in the following. The simplest is to only consider coarse cells with a fraction of at least $50 \%$ of change from Landsat. Another option is to select the intersection between both errors for a set of fractions. Third, one may choose the minimum cost according to a user-defined (here hyperbolic) cost function for the bidimensional error space. In the following we will first assess the results for the Pareto boundary and then for the actual MODISLandsat change data.

4.4.1 Error for Pareto boundary: The Pareto boundary forms a line of optimal classifications for a set of different fractions. The asymmetric curves in Figure 4A indicate a skewed error distribution and Table 7 shows best result for above-mentioned criteria. Assuming "change fraction $>=50 \%$ " the error for Landsat is almost twice as high as for MODIS. Employing the criterion of an equal error between Landsat and MODIS resulted in lower costs than the $50 \%$ threshold. All selected change fractions were smaller than $50 \%$ which indicates that cells with less than $50 \%$ change proportion in Landsat are deemed sufficient for defining change in MODIS. The lowest cost criterion decreases the cost slightly as compared to the intersection between both errors, which in all cases also resulted in an even lower change fraction. This indicates that using the $50 \%$ fraction is clearly inappropriate in this analysis, i.e. change fractions of approximately $30 \%$ should be employed. Also, the error for Landsat dropped further and is often just half as much as for MODIS. This result is meaningful as change detection with Landsat should be more accurate than with MODIS.

The direct change detection between 2005 and 2010 shows generally lower costs and comparatively lower errors than accumulative annual change detection between those years. It becomes also clear that Landsat products with larger MMUs, which reduce the noise in change detection maps, resulted in lower costs and thus smaller errors.

4.4.2 MODIS-Landsat change data: In comparison to the Pareto boundary, change comparison between MODIS and Landsat shows high errors (Figure 4B, Table 8). For accumulative changes, assuming the $50 \%$ threshold, errors for MODIS and Landsat were almost equal, thus these results are very similar to criterion of error intersection. For direct comparison between 2005 and 2010 Landsat, errors were very high and MODIS moderate. However, the errors curves of both data sets never intersected with increasing change fractions and thus the equal error measure cannot be used for assessment. The lowest cost resulted in fractions between 30 and $40 \%$ for accumulative change and above $90 \%$ for direct change. Notable is the higher error for Landsat than MODIS, which could indicate issues in the Landsat data set.

\begin{tabular}{|c|c|c|c|c|c|c|}
\hline & \multicolumn{3}{|c|}{ Accumulative } & \multicolumn{3}{|c|}{ Direct } \\
\hline & lha & 5 ha & 10ha & 1ha & 5 ha & 10ha \\
\hline \multicolumn{7}{|c|}{ Change fraction $>=50 \%$} \\
\hline Cost & 70.78 & 62.40 & 55.89 & 64.46 & 55.19 & 46.06 \\
\hline Landsat error & 59.25 & 48.31 & 40.81 & 52.23 & 40.41 & 31.22 \\
\hline MODIS error & 28.29 & 27.26 & 25.48 & 25.61 & 24.81 & 21.58 \\
\hline \multicolumn{7}{|c|}{ Equal error between Landsat and MODIS } \\
\hline Fraction & 35 & 39 & 40 & 37 & 42 & 44 \\
\hline Cost & 65.98 & 58.57 & 53.50 & 60.55 & 52.57 & 44.58 \\
\hline Error & 41.36 & 35.56 & 31.66 & 36.50 & 30.40 & 25.93 \\
\hline \multicolumn{7}{|l|}{ Lowest cost } \\
\hline Fraction & 26 & 27 & 33 & 29 & 29 & 33 \\
\hline Cost & 64.62 & 56.93 & 52.45 & 59.40 & 51.05 & 43.62 \\
\hline Landsat error & 29.60 & 21.21 & 24.86 & 27.89 & 18.55 & 16.66 \\
\hline MODIS error & 49.74 & 45.34 & 36.72 & 43.70 & 39.91 & 32.36 \\
\hline
\end{tabular}

Table 7. Cost, fraction and error statistics (all in percent) for the Pareto boundary. 


\begin{tabular}{|c|c|c|c|c|c|c|}
\hline & \multicolumn{3}{|c|}{ Accumulative } & \multicolumn{3}{|c|}{ Direct } \\
\hline & 1ha & 5 ha & 10ha & 1ha & 5 ha & 10ha \\
\hline \multicolumn{7}{|c|}{ Change fraction $=\mathbf{5 0} \%$} \\
\hline Cost & 97.76 & 97.72 & 97.63 & 95.86 & 95.69 & 94.76 \\
\hline Landsat error & 87.15 & 86.42 & 84.83 & 92.38 & 92.06 & 90.23 \\
\hline MODIS Error & 82.59 & 83.19 & 86.39 & 45.69 & 45.69 & 46.37 \\
\hline \multicolumn{7}{|c|}{ Equal error between Landsat and MODIS } \\
\hline Fraction & 60 & 58 & 52 & NA & NA & NA \\
\hline Cost & 97.88 & 97.88 & 97.64 & NA & NA & NA \\
\hline Error & 85.59 & 85.59 & 84.75 & NA & NA & NA \\
\hline \multicolumn{7}{|l|}{ Lowest cost } \\
\hline Fraction & 42 & 35 & 32 & 93 & 93 & 93 \\
\hline Cost & 97.57 & 97.46 & 97.43 & 93.67 & 93.67 & 93.65 \\
\hline Landsat error & 88.35 & 88.70 & 87.20 & 80.71 & 80.71 & 80.66 \\
\hline MODIS error & 79.11 & 77.35 & 79.95 & 67.17 & 67.17 & 67.17 \\
\hline
\end{tabular}

Table 8. Cost, fraction and error statistics (all in percent) for MODIS versus Landsat change data.

Similar to Pareto boundary assessment, the errors were lower for direct change detection than accumulative change and slightly diminished with larger MMUs, however, this effect was less notable.

\section{DISCUSSION AND CONCLUSIONS}

A major presumption for all successful change detection studies using spatial data sets is near-to-perfect spatial co-registration (Lu et al. 2004, Boschetti et al. 2004, Colditz et al. 2014b). In this study we only performed visual comparisons among different data sets. We could not find noteworthy spatial displacements, which confirms the generally good spatial registration of MODIS and Landsat data (Wolfe et al. 2002, Masek et al. 2006) and thus good co-registration between both sensors. An approach for quantitative analysis of spatial coregistration between data sets of different spatial resolution was shown in Colditz et al. (2012a) and applied to change detection in Colditz et al. (2014b).

\subsection{Annual versus five year intervals}

There are notable differences in temporal scales that differed by sensor products. For MODIS, accumulative annual change showed larger change area than direct change between 2005 and 2010. Given that the data sets (MODIS monthly composites) and change detection method (bi-annual normalized difference images) were the same, the reason is related to the time intervals. This pattern was expected as many changes occur abruptly and may persist only for a short interval. For instance, plots for the above-mentioned slash-and-burn agriculture only exist a few years before the land is abandoned and secondary, mostly shrubby vegetation regrows before tropical forest takes over in several successional stages. Some changes may not be observable even at annual scales, e.g. burnt areas in pastures and low shrubby vegetation (Ressl et al. 2009, Colditz et al. 2014).

Even though annual accumulative changes detect larger total area than direct changes over several years, the locality of changes differs. The main reason is that change detection at annual intervals can hardly reveal subtle change processes at a slower pace over several years. Despite the availability of trendbased and time series analysis techniques for detecting change processes (Kennedy et al. 2010, Latifovic and Pouliot 2014,
Verbesselt et al. 2010), bi-annual difference images over longer time scales may be an alternative.

Landsat change results show a contrary pattern with more changes detected for direct comparison between 2005 and 2010 than accumulative annual changes. In this case the reason is likely related to differences in visual change detection. Even though we intended to harmonize visual digitalization among different analysts, the issue could not be fully resolved. The analyst that detected changes between 2005 and 2010 directly worked approximately three weeks on this data set while the other, responsible for annual change detection between 2005 and 2010, spent less than two weeks for all five data sets (two days per bi-annual data set). Post-processing and applying minimum mapping units could not fully resolve the differences in the level of detail between both data sets.

\subsection{Spatial resolution}

The number of patches depends on the spatial resolution and minimum mapping unit. The reduction of small patches was illustrated for Landsat which highly affected the number of patches but only moderately the area. Notable is also the similarity between the patches per square kilometre for Landsat with 5ha MMU and MODIS with a cell size of 6.25 ha at the national level.

Relating spatial scales is still an emerging topic with only a few studies. For the dichotomous case as in this study (change / no change) we adapted algorithms from file monitoring (Boschetti et al. 2004, Ressl et al. 2009, Csiszar et al. 2006, Morisette et al. 2005). The Pareto boundary, adapted to spatial data in the field of remote sensing by Boschetti et al. (2004), indicates the optimal line for a set of change fractions. The area below this curve cannot be reached due to differences in the spatial resolution between both data sets. The lower errors for Landsat data with larger MMU are therefore meaningful as the difference in resolution diminishes with increasing MMUs of finer spatial resolution data. Nevertheless, in absolute terms the Pareto boundary is still high, in comparison to Boschetti et al. (2004) or Colditz et al. (2014b).

The analysis of different criteria for defining an appropriate change fraction analysed three approaches. The rationale for choosing the $50 \%$ threshold is simply that of the majority rule, i.e. the class that makes up the largest proportion of area will be assigned. Although valid in some cases this assumption does not hold up to reality due to an uneven probability distribution function. For instance, a pixel in coarser resolution data may be flagged even though the area proportion that corresponds to this class is much smaller, a case frequently found in fire mapping (Ressl et al. 2009). Choosing the equal value between both errors may be desirable in some cases but many studies prefer to minimize one of the two errors (Colditz et al. 2014b). The intersection may even not exist as we have shown for direct comparisons. The lowest cost could be a viable alternative; however the actual fraction and errors highly depend on the selected cost function. This study and others (Boschetti et al. 2004, Colditz et al. 2014b) have deemed useful the hyperbolic cost function as defined in equation 3 .

In general there is a poor relation between Landsat and MODIS change detection products, also noted by the high difference between Landsat-MODIS data comparison and the Pareto boundary, which is related to two major facts. First, MODIS change was extracted from a product designed for the national 
scale which in some areas works well but in this site relatively poor, mainly due to changes that are too small to detect at $250 \mathrm{~m}$ spatial resolution, that cannot be discerned spectrally, that occur on different time scales, as well as remaining data issues due to frequent cloud cover during rainy season from May to September (Colditz et al. 2014b). The second reason is the approach of visual analysis of Landsat with two different analysts that worked at different levels of detail. This introduced inconsistencies to our data set which we could not fully resolve. It would have been desirable to obtain automatically detected changes with Landsat or even higher spatial resolution data, but opportunities are limited due to inconsistent image acquisition. For instance, Landsat 5TM was turned off over the study area from 2002 to 2009 and Landsat 7ETM+ images suffer from scan-line off data gaps in addition to frequent could cover and shadows. In order to obtain larger areas of valid data two images were composited. The selected image dates, which differ in 2008 and 2010 from the normal pattern of choosing images at the end of the dry season, illustrate the difficulties of finding appropriate data.

\section{ACKNOWLEDGEMENTS}

We kindly thank our analysts Cesar Feliciano Rodriguez and Armando Gandarilla Ramirez for digitizing change from Landsat image composite pairs.

\section{REFERENCES}

Boschetti, L., Flasse, S. P., \& Brivio, P. A., 2004. Analysis of the conflict between omission and commission in low spatial resolution dichotomic thematic products: The Pareto Boundary. Remote Sensing of Environment, 91(3-4), pp. 280-292.

Colditz, R. R., Acosta-Velázquez, J., Díaz Gallegos, J. R., Vázquez Lule, A. D., Rodríguez Zúñiga, M. T., Maeda, P., Ressl, R., 2012a. Potential effects in multi-resolution postclassification change detection. International Journal of Remote Sensing, 33(20), pp. 6426-6445.

Colditz, R. R., López Saldaña, G., Maeda, P., Argumedo Espinoza, J., Meneses Tovar, C., Victoria Hernández, A., Ressl, R., 2012b. Generation and analysis of the 2005 land cover map for Mexico using 250m MODIS data. Remote Sensing of Environment, 123, pp. 541-552.

Colditz, R. R., Pouliot, D., Llamas, R. M., Homer, C., Latifovic, R., Ressl, R. A., Richardson, K., 2014a. Detection of North American Land Cover Change between 2005 and 2010 with 250m MODIS Data. Photogrammetric Engineering \& Remote Sensing, 80(10), pp. 918-924.

Colditz, R. R., Llamas, R. M., \& Ressl, R., 2014b. Detecting Change Areas in Mexico Between 2005 and 2010 Using $250 \mathrm{~m}$ MODIS Images. IEEE Journal of Selected Topics in Applied Earth Observations and Remote Sensing, 7(8), pp. 3358-3372.

Coppin, P., Jonckheere, I., Nackaerts, K., Muys, B., \& Lambin, E., 2004. Review ArticleDigital change detection methods in ecosystem monitoring: a review. International Journal of Remote Sensing, 25(9), pp. 1565-1596.

Csiszar, I. A., Morisette, J. T., \& Giglio, L., 2006. Validation of Active Fire Detection From Moderate-Resolution Satellite Sensors: The MODIS Example in Northern Eurasia. IEEE
Transactions on Geoscience and Remote Sensing, 44(7), pp. $1757-1764$.

Kennedy, R. E., Townsend, P. A., Gross, J. E., Cohen, W. B., Bolstad, P., Wang, Y. Q., \& Adams, P., 2009. Remote sensing change detection tools for natural resource managers: Understanding concepts and tradeoffs in the design of landscape monitoring projects. Remote Sensing of Environment, 113(7), pp. 1382-1396.

Kennedy, R. E., Yang, Z., \& Cohen, W. B., 2010. Detecting trends in forest disturbance and recovery using yearly Landsat time series: 1. LandTrendr - Temporal segmentation algorithms. Remote Sensing of Environment, 114(12), pp. 2897-2910.

Latifovic, R., Homer, C., Ressl, R., Pouliot, D., Hossain, S. N., Colditz, R. R., Victoria, A., 2012. North American LandChange Monitoring System. In: Remote Sensing of Land Use and Land Cover: Principles and Applications, Boca Raton, FL., pp. 303-324.

Latifovic, R., \& Pouliot, D., 2014. Monitoring Cumulative Long-Term Vegetation Changes Over the Athabasca Oil Sands Region. IEEE Journal of Selected Topics in Applied Earth Observations and Remote Sensing, 7(8), pp. 1-13.

Lu, D., Mausel, P., Brondízio, E., \& Moran, E., 2004. Change detection techniques. International Journal of Remote Sensing, 25(12), pp. 2365-2401.

Masek, J. G., Vermote, E. F., Saleous, N. Z., Wolfe, R. E., Hall, F., Huemmrich, Lim, T. K., 2006. A Landsat surface reflectance dataset for North America, 1990-2000. Geoscience and Remote Sensing Letters, IEEE, 3(1), pp. $68-72$.

Morisette, J. T., Giglio, L., Csiszar, I., \& Justice, C. O., 2005. Validation of the MODIS active fire product over Southern Africa with ASTER data. International Journal of Remote Sensing, 26(19), pp. 4239-4264.

Pouliot, D., Latifovic, R., Fernandes, R., \& Olthof, I., 2009. Evaluation of annual forest disturbance monitoring using a static decision tree approach and 250 m MODIS data. Remote Sensing of Environment, 113, pp. 1749-1759.

Pouliot, D., Latifovic, R., Zabcic, N., Guindon, L., \& Olthof, I., 2014. Development and assessment of a $250 \mathrm{~m}$ spatial resolution MODIS annual land cover time series (2000-2011) for the forest region of Canada derived from change-based updating. Remote Sensing of Environment, 140, pp. 731-743.

Quinlan, J. R., 1994. C4 . 5 $\square$ : Programs for Machine Learning. Machine Learning, 16, pp. 235-240.

Ressl, R., Lopez, G., Cruz, I., Colditz, R. R., Schmidt, M., Ressl, S., \& Jiménez, R., 2009. Operational active fire mapping and burnt area identification applicable to Mexican Nature Protection Areas using MODIS and NOAA-AVHRR direct readout data. Remote Sensing of Environment, 113(6), pp. $1113-1126$.

Tapiador, F. J., \& Casanova, J. L., 2003. Land use mapping methodology using remote sensing for the regional planning directives in Segovia, Spain. Landscape and Urban Planning, 62(2), pp. 103-115. 
Verbesselt, J., Hyndman, R., Newnham, G., \& Culvenor, D., 2010. Detecting trend and seasonal changes in satellite image time series. Remote Sensing of Environment, 114(1), pp. 106115 .

Wolfe, R. E., Nishihama, M., Fleig, A. J., Kuyper, J. a., Roy, D. P., Storey, J. C., \& Patt, F. S., 2002. Achieving sub-pixel geolocation accuracy in support of MODIS land science. Remote Sensing of Environment, 83(1-2), pp. 31-49.

Zhu, Z., \& Woodcock, C. E., 2012. Object-based cloud and cloud shadow detection in Landsat imagery. Remote Sensing of Environment, 118, pp. 83 - 94. 